\title{
Technology Demand Assessment of Adaption of Chinese Cities to Climate Change
}

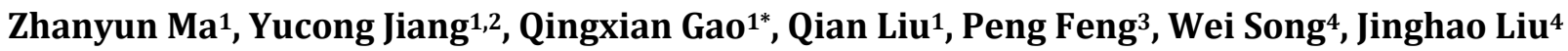 \\ ${ }^{1}$ State Key Laboratory for Environmental Benchmarks and Risk Assessment, Chinese Research Academy of Environmental \\ Sciences, Beijing, China \\ ${ }^{2}$ Capital Normal University, Beijing, China \\ ${ }^{3}$ China Centre for Resources Satellite Data and Applications, Beijing, China \\ ${ }^{4}$ China Urban Construction Design \& Research Institute Co., Ltd., Beijing, China \\ Email: gaoqx@craes.org.cn
}

How to cite this paper: Ma, Z. Y., Jiang, Y. C., Gao, Q. X., Liu, Q., Feng, P., Song, W., \& Liu, J. H. (2019). Technology Demand Assessment of Adaption of Chinese Cities to Climate Change. Journal of Geoscience and Environment Protection, 7, 338-353. https://doi.org/10.4236/gep.2019.78023

Received: March 29, 2019

Accepted: August 26, 2019

Published: August 29, 2019

Copyright () 2019 by author(s) and Scientific Research Publishing Inc. This work is licensed under the Creative Commons Attribution International License (CC BY 4.0).

http://creativecommons.org/licenses/by/4.0/

(c) (i) Open Access

\begin{abstract}
Climate change adaptation is the process of preparing and actively adjusting to meet the climate change (negative effects and potential opportunities). Urban adaptation is aimed at the sensitivity level of risks and specific impacts of cities under the impact of climate change, and to develop policies and investment programs to reduce the vulnerability of cities to climate change risk. Urban adaptive action provides the basis and direction for the construction of urban resilience and sustainable development. Identifying the demand of adaption technologies, promoting the practical implementation of international technology transfer and reducing domestic emissions have important significance for the global response to climate change and improvement of the ability of urban adaptation. In this paper, through in-depth analysis on the concept and connotation of climate change, climate disasters and urban adaptation to climate change, the evaluation framework and steps of urban adaptation to climate change technology are determined, and six priority application technologies which can maximize the overall efficiency of sustainable development, improve the ability to adapt to climate change and at the same time reduce the cost at the greatest extent are identified.
\end{abstract}

\section{Keywords}

Chinese Cities, Adaptation to Climate Change, Framework and Steps of Technology Assessment, Priority Technologies on Climate Change Adaptation

\section{Introduction}

Climate change has become the biggest environmental challenge that human is 
facing. Population and capitals are concentrated in cities. Cities are crucial for the survival of mankind and the social development. Cities are confronted with significant impacts of current and future climatic change. These impacts may lead to serious consequences to the health, livelihoods and assets of people. Climate-friendly technology used by cities to respond to climate change includes mitigation technology and adaptation technology. They are indispensable and complementary to each other. Control of the concentration of atmospheric greenhouse gas in the mitigation strategy is a fundamental way to suppress global climate change, but global warming will continue for quite a long time because of the constant enlargement of the scale of the world economy and the great inertia of the climate system. Proactive and planned adaptation actions can not only effectively reduce the adverse effects of climate change, but also make full use of favorable factors caused by climate change, while avoiding disadvantages, and turning challenges into new development opportunities (Han et al, 2012). Adaptation of cities to climatic change has become one of key points of responding to climatic change at present. Adaptation technology demand assessment can lay the solid foundation for urban planning of the state. Through the effective governance of multi-level city risks, formulation of supporting measures and policies, adaptation capacity improvement of the local government and communities, coordination and participation of private department, and development and construction of corresponding capital sources and organizations, the urban adaptation actions provide the basis and guidance to build urban resilience and realize sustainable development. In addition, through the analysis on adaption technology gap and technology transfer and development obstacles at home and aboard, recognition of the adaption technology demand, and promotion of the practical work of international technology transfer, China has advanced adaption technology quickly, and domestic emissions are reduced, which has important significance to global response to climate change and improvement of the adaption ability of cities.

Through the research on the adaptation technology demand assessment of cities, adaption technology gap and technology transfer and development obstacles at home and aboard can be defined, the adaptation technology demand in China can be identified, and the intentional transfer of technology can be promoted. Finally, China will have advanced adaption technology quickly, and domestic emissions will be reduced. At the same time, technical support can be provided to the pilot work for adaptation of China's cities to climatic change. There're many researches and papers about mitigation technology. The adaption technology involves a wide range of fields, but there are few researches and papers of relevant adaption technologies. Therefore, adaptation technology demand assessment is more difficult, more significant and more important than mitigation technology demand assessment.

IPCC reported that climatic change would increase the uncertainty of occurrence of disaster risks, and global extreme weather and climate events and their 
impacts would be increased and aggravated continuously in the future. Currently, in the background of climatic change, many extreme events exceed the scope of human knowledge and experience, and even the developed countries with perfect capacity of disaster prevention and reduction and emergency management also inevitably lose patience in coping with the disasters caused by climatic change. Under the attack of disasters caused by climatic change, the urban decision makers of the countries such as Canada, US, Australia and EU have recognized the importance of coping with climatic disaster risks, and worked out urban disaster prevention plans or adaptation plans successively. Their experience and lessons are worth learning by China.

For example, Vancouver has conducted many positive attempts and explorations in the selection of strategies for adapting to climatic change for the purpose of water environment protection, and formulated several policies for water environment protection involving drinking water quality management and protection, water resource saving, wastewater treatment, rainwater management, etc (Ma, Mao, \& Shen, 2014). US President Barack Obama issued the executive order "Getting Ready for Coping with Climatic Change Impacts in the US", which included seven sectors ( $\mathrm{Du}, 2014$ ). It also became the important component of the "Presidential Climatic Change Action" to enhance the ability of the US to prevent climatic disasters comprehensively. Australia relevant improved relevant policies and regulations, and raised the original urban plan and disaster prevention standard (Feng \& Zhou, 2012). The adaptation measures of EU for climatic change are promoted stage by stage (Zeng \& Qu, 2013). They are composed of the fundamental work stage, the stage of improvement of EU's ability to respond to climate change and the comprehensive adaptation strategy implementation stage.

\section{Technology Demand Assessment Method of Chinese Cities' Adaption to Climate Change}

\subsection{Defining the Concept and Connotation of the Adaptation of Cities to Climatic Change}

\subsubsection{Definition and Impact of Climate Change}

Climate change refers to huge change of average climate state statistically or long-time climate change (typically 30 years or more) (Liu, Ge, \& He, 2010). Climate change includes the variation of both average value and rate of change. That is, one or two of average climate state and climate deviation (anomaly) are changed remarkably statistically. A larger climate deviation value means larger amplitude of climate change and more instable climate state.

Extreme climate (extreme weather or climate event) refers to a weather or climate variable value which is higher (or lower) than a threshold value near the upper limit (or lower limit) of the observation value range of the variable (Luo, 2012). In short, extreme weather event and extreme climate event are jointly known as "extreme climate". Few extreme events mean very few data which can be used to evaluate the frequency and intensity of these events. The fewer such events are, the more difficult it is to identify their long-term variation. 
The impacts of climate change are comprehensive and complex, and involve multiple sectors and departments. The cities of developing countries are affected by climate change more easily because of facing development challenges such as poverty, weak infrastructure, environmental degradation, limited resources, insufficient capacity, etc. China is one of countries which are affected adversely by climate change most seriously. The impacts of climate change on China not only include aggravation of glacial ablation and increase of extreme climate events, but also the impacts on departments such as agriculture and animal husbandry, forest and natural ecological system, water resources and coastal zones or other sectors such as socio-economic field in China.

\subsubsection{Definition and Connotation of Meteorological Disaster}

Meteorological disaster refers to the direct or indirect damage caused by atmosphere to human life and property, national economy construction, national defense construction, etc. Meteorological disaster is one of primary disasters among natural disasters. Climatic disaster refers to the disaster caused by climate anomalies to human living and production in general.

Meteorology includes two concepts, which are weather and climate, so meteorological disasters include weather disasters, climatic disasters, meteorological secondary and derived disasters, etc. Climatic disaster and weather disaster differ in concept, but they have a close internal relation.

\subsubsection{Concept and Connotation of the Adaptation of Cities to Climate Change}

With population growth and the process of urbanization, there is a great difference between urban development and the capacity of responding to climate change risks in many cities, and the climatic risks and vulnerability caused by extreme climate events to cities have also been increasingly emerging in the general background of global climate change.

Adaptation refers to adjustment measures, policy scheme or science and technology used by the natural, social or economic system aimed at mitigating adverse effects or taking advantage of beneficial effects to deal with the actual or expected influence which the climate leads to (IPCC, 2007). In response to urban climate change, mitigation and adaptation supplement each other, and both of them are indispensable. However, the current greenhouse gas emission level is very low in most developing countries, they are in the historical development stage of industrialization and urbanization and have quickly increased energy demand, and emission reduction is their long-term arduous task; in addition, the adverse impacts of climate change on developing countries are more remarkable, so adaptation has higher reality and urgency. Adaptation is not a simple solution, but a process of managing risks in a fragile environment. New features of disaster occurrence in cities have appeared due to the change of climatic conditions and characteristics of the underlying layer of cities. Therefore, a city shall be an area which preferentially adapts to climate change. 


\subsection{Framework and Steps of Urban Adaptation to Climate Change Technology Assessment}

Cities are the main power of growth and development, so they must resist climate change effect and make adjustment to adapt to continuous and future climate change impacts. This is especially critical to developing countries. It is more complex to adapt to the climate change, because besides the general factors, including advancement of technology, adaption benefits, cost and environmental impacts, the applicability of relevant technologies in different regions and those in development stages also need to be evaluated. Therefore, the reasonable technical route shall be established, so as to comprehensively and accurately identify important areas and key technologies, and assess the technology demand of adaption of cities to the climate change. The main steps include:

1) Analyze characteristics of urban climate risks in China, and different types of cities main climate change risks and risk factors such as vulnerability and exposure;

2) According to different risks, identify and prioritize the key sectors and subsectors of the adaption of Chinese cities to climate change;

3) Identify and prioritize the climate technology adaption technologies which can reduce vulnerability and exposure;

4) Conduct case studies on key technologies, and analyze the technology gap and technology transfer and development obstacles at home and aboard;

5) Negotiate with the stakeholders, and reach an agreement on key issues.

\subsection{Priority Areas for Urban Adaptation to Climate Change and Technical Evaluation Method}

\subsubsection{Evaluating the Key Climate Change Risks of Cities}

Climate change risks are determined by hazards, exposure and vulnerability (Yin, Sun, \& Li, 2012). China has a vast territory and complicated terrain conditions. The above three indicators have significant differences between regions and sectors. On the basis of fully collected information, the key climate change risks faced by Chinese cities shall be identified. Table 1 gives the index system in the risk evaluation of climate change and climate change risks, including direct weather and climate disasters (e.g. extreme high temperature, heavy rainfall, drought, sea level rise, etc.) and indirect disasters (e.g. epidemic disease, food shortage, energy demand fluctuation, environmental pollution, traffic and communication interrupt, ecological system destruction, etc.). Weighted evaluation of these risks is made respectively in terms of disaster, exposure degree and vulnerability.

Risk evaluation is a process of recognizing risk essence and deciding risk level. The information on the distribution, pattern, variation, etc. of risks and their vulnerability can be understood through risk evaluation. This is of great guidance significance to coping with disaster risks in the background of climate change. The adverse impacts of climate change on the human system are reflected mainly by vulnerability and exposure degree. Unbalance of the social economy development process and the complexity of non-climate factors lead to 
Table 1. Index system for the evaluation of climate change risks.

\begin{tabular}{llll}
\hline & Hazard & $\begin{array}{l}\text { Index } \\
\text { Strength }\end{array}$ & Weight \\
Climate change risks: & & Population \\
$\begin{array}{l}\text { Extreme high temperature, } \\
\text { heavy rainfall events, drought, } \\
\text { sea level rise, epidemic disease, } \\
\text { food shortage, energy demand } \\
\text { fluctuation, environmental } \\
\text { pollution, traffic and }\end{array}$ & $\begin{array}{l}\text { Exposure degree } \\
\text { (combination of } \\
\text { communication interrupt, }\end{array}$ & $\begin{array}{l}\text { Per capita GDP } \\
\text { destroy of ecosystems, etc. }\end{array}$ & $\begin{array}{l}\text { Per capita construction area } \\
\text { Others }\end{array}$ \\
& Vulnerability & $\begin{array}{l}\text { Ability to predict and } \\
\text { avoid hazards }\end{array}$ \\
& & $\begin{array}{l}\text { Ability to respond to hazards } \\
\text { Abe impact of hazards }\end{array}$ \\
& & Ability to recover \\
\hline
\end{tabular}

a great difference in vulnerability and exposure degree, and form different climate change risks.

Exposure degree means that personnel, livelihood, environmental services, various resources, infrastructure, economy, society and cultural assets are located at the position where they may suffer from adverse impacts (Zheng, Sun, \& $\mathrm{Li}, 2012$ ). Vulnerability refers to the sensitivity or fragility of the receptor system to adverse impacts of climate change (Li, Zhang, \& Cheng, 2008). Vulnerability is defined as the degree of easily suffering from various adverse impacts of climate change but inability to cope with them by a system in the fourth evaluation report of IPCC, including climatic variability and extreme events. Exposure degree is the necessary condition of vulnerability, but not its sufficient condition. In some cases, exposure degree may be high, but vulnerability is not high. For example, the exposure degree of plains where flood occurs easily is high, but their vulnerability is relatively low in case of improving the structure of buildings or mitigating potential losses with methods or technologies. However, if an environment is fragile to extreme events, its exposure degree is inevitably high. For extreme weather and climate events with low probability and high intensity, the losses from disasters are explained using intensity and exposure degree more extensively than using vulnerability. However, for non-extreme events with high probability and low intensity, e.g. disasters which occur at national and local scales for multiple times but have low intensity, the vulnerability of exposure elements is of great significance to explaining the causes for losses from disasters (Yin, Sun, \& Li, 2012).

We shall understand exposure degree and vulnerability multi-dimensionally and overall in the background of climate change and attach importance to risk communication and risk accumulation. This can help us to correctly select risk evaluation and management methods and transfer and share risks. We shall continuously improve the capacity of coping and adaptation while preventing and responding to disaster risks; design and implement effective disaster risk 
management strategies and make it possible to adapt to climate change.

\subsubsection{Identifying Priority Sectors}

The priority sectors are selected based on the scale and range of climate impact and their significance to China's economic development. Each sector can be further divided into several subsectors. Technology demand assessment needs to identify those subsectors with the most effective adaptation based on the vulnerability assessments. The adaption of cities to climate change is primarily identified in the following aspects.

Improve the infrastructures. To address risks of floods, storm, sea level rise, low temperature, ice and snow, high temperature and other adverse effects, and to ensure the supply of urban energy and water and traffic and communication safety;

Improve the public health. To address the challenges of high temperature, heat waves, epidemics, etc.;

Improve the monitoring and early warning ability. To reduce the vulnerability by improving the reaction capacity of cities to extreme climate events;

Enhance the municipal administration and financial support. Ensure that all levels of government, many industries and the general public have motivation and ability in the process of implementation of various adaptation measures;

Improve urban planning, consider urban adaptation strategy and measures in the urban planning stage, and avoid blind site selection and construction;

Adjust urban industrial structure, and ensure that the adjusted urban industrial structure adapts to the urban adaptation strategy, so that the urban industrial structure and layout can meet the production environment and market demand changed with climate change.

The next step is to prioritize the identified subsectors based on their maximum adaptation net benefits. Vulnerability assessments can be used to identify subsectors with the most effective adaptation. The priority of subsectors is assessed by comparing the economic, environmental, social priorities and the degree of vulnerability deduction of the subsectors. According to the current development strategy planning, the subsectors with a stable economic growth and transformation and development model should have a higher priority. In this paper, we obtain the sort of the priority areas for urban adaptation to climate change by using statistics of experts scoring situation in four priority development, see Chart 3-1.

\subsubsection{Identification and Determination of Priority Technology}

Once the priority of subsectors is determined, then technologies to mitigate climate vulnerability and exposure degree of targeted subsectors can be chosen. The goal is to identify the technologies that maximize total benefits of sustainable development and vulnerability reduction while minimizing costs. The identified adaptation technologies need to be relevant to the country conditions and climate mitigation. 
Technologies for adaptation can be categorized into three groups by the adaptation strategy, including protection, retreat and accommodating. Adaptation also includes active adaptation and passive adaptation. Through the collection of domestic and foreign literature data, comparative analysis and summary, we can summarize the detailed table of urban adaptation technology in subsectors, and then filter technologies according to the different needs.

For more detailed assessment, technologies can be further categorized based on the scale of application (large- or small-scale project), time span (long-, medium- or short-term project), availability and the forms (non-marketable "know-hows" and hard technologies like physical assets).

After selecting prioritizing subsectors and their relevant adaptation technologies, identification and selection of technologies become key points. The methodology for technology demand assessment depends on the quantity of available data and information. If a technology has sufficient quantitative data and information, a formal decision analysis can be used to prioritize the technologies options. Otherwise, the more qualitative case studies can be applied to the relevant technologies. Technologies are identified and demand is evaluated in this study combining the decision analysis method with the qualitative case research method.

The first stage is to discuss about and determine appropriate criteria and indicators for prioritizing technologies. Through literature survey and analysis, currently the related evaluation indicators should include climate change resilience indicator, contribution to the prioritized development areas, application cost, etc. An appropriate set of indicators which can reflect the contribution of the technology on the environmental, social, economic and technological fields shall be established. This is the key to demand assessment.

The second stage is to assign the weights of these indicators determined among stakeholders. The methodology to derive the weights is similar to the one that is used to prioritize subsectors. Once the indicators and corresponding weights are determined, a final assessment decision can be made by using an appropriate valuation. Valuation methodologies include Multi-Criteria Decision Analysis (MCDA) (Meng \& Li, 2013; Zuo, 1987), economic decision rule (Wang, 2005), etc. Both methods need sensitivity analysis to adjust for risks and uncertainties.

\subsection{Gap between Technologies and Analysis of Obstacles to Popularization of Technologies}

\subsubsection{Analysis on the Gap between International and Domestic Technologies}

Although China has made impressive progress in indigenous research and development, there are still significant gaps between the practice in China and the best practice in the world. The gaps may be explained by the weak institutional capacity in nurturing R\&D, barriers of technology diffusion and transfer, insufficient investment incentives, etc. By closing these gaps, China can improve its productivity effectively and improve the ability of cities to adapt to climate change. 
For each identified adaptation technology in China, it needs to be compared with the international best practices. This process involves three steps. The first step is to identify the corresponding "state-of-the-art" foreign technology. Second, the potential of technical progress for the technology in China compared with the global best practice technologies. The third step is to identify and analyze the existing gaps and project changes of the technology in the future.

The purpose of the technology gap analysis is not just to compare the gaps between domestic and international practices. The ultimate goal is to analyze the cause of the gaps and make policy recommendations, in order to facilitate domestic technology innovation and international technology transfers.

\subsubsection{Analysis of Obstacles to Technology Transfer and Diffusion}

Technology commercialization depends on the incentive mechanism, management method and technical development and creation capacity of stakeholders. To achieve successful technology transfer, the transfer cost shall be controlled effectively, so as to meet the need of economical feasibility, and there is also a need for technical personnel's participation. The obstacles to technology transfer or diffusion may come from resistance to "creative destruction" by new technologies, worries about social structure changes caused by technical change or the factors such as credit restriction, low-efficiency management, market failure, lack of information, etc.

\section{Select Priority Technologies on Climate Change Adaptation in Chinese Urban Area}

\subsection{Priority Subsectors}

According to methodological requirements with expert scoring method with reference to the marking table in methodologies, the six subsectors (including the developing infrastructure, improving public health, improving monitoring and early warning capability, strengthening urban management and financial support, improving urban planning and adjusting industrial restructuring) were scored and ranked with the criterions of environmental, economic, social, and vulnerability reduction potential. See Table 2 for the score.

By the above table, it can be seen that the developing infrastructure ranks the first, followed by improving monitoring and early warning capabilities and improving urban planning, and then improving public health, the adjustment of industrial structure. Therefore, developing infrastructure, improving monitoring and early warning capabilities and improving urban planning are evaluated as priority subsectors.

\subsection{Determining the Weight of Criteria}

Analytic Hierarchy Process (AHP) is applied to rank the applicable technologies through the decision criteria of pairwise comparison relying on expert judgment to determine the priority technologies. The basic idea of AHP model is that relative judgments are more reliable than absolute judgments. Analytic Hierarchy 
Table 2. Subsector prioritization matrix.

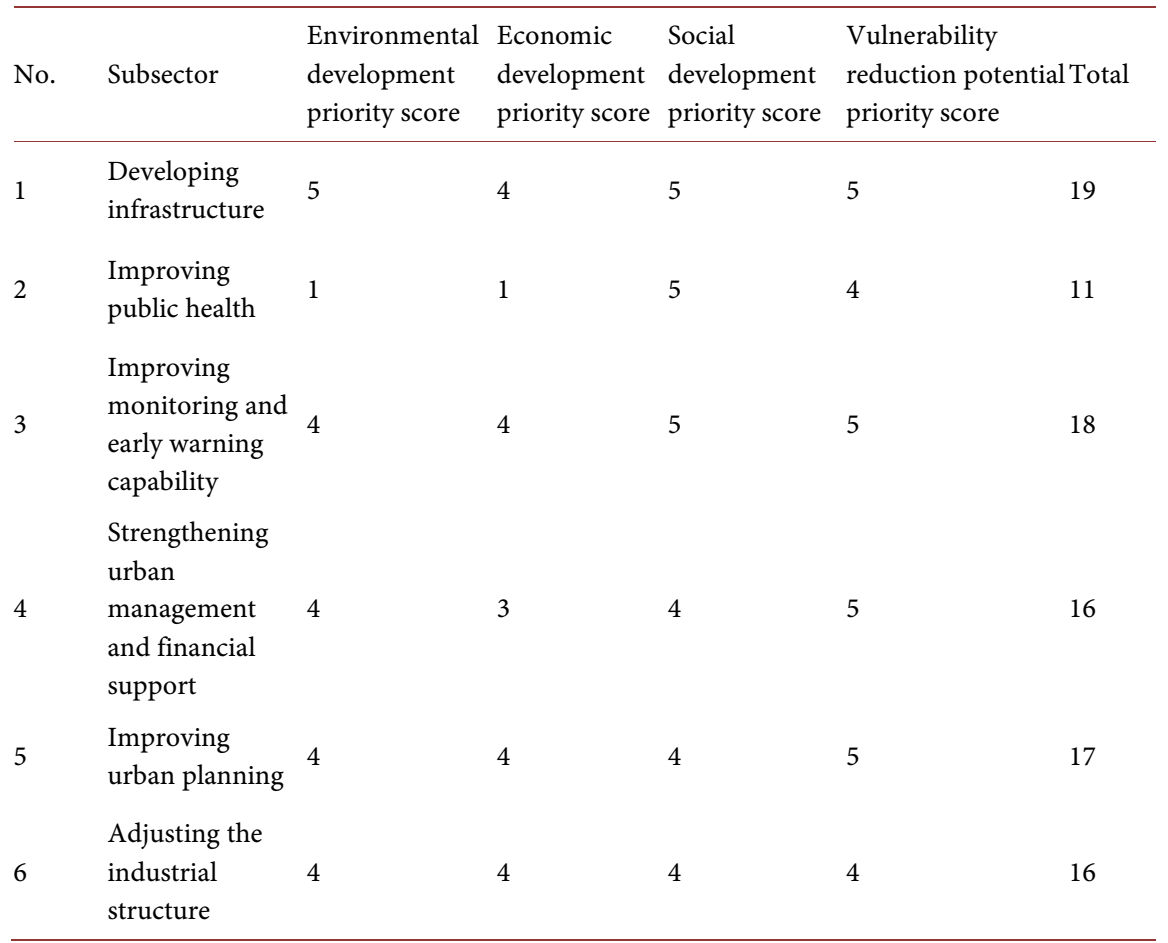

*The score range is $0-5$ points, where 0 indicates no contribution/impact, and 5 points represent the greatest contribution/impact.

Process is divided into three steps. The first is to determine the weight rule layer, the second is to calculate the relative importance of the criteria for the single criterion, the third is to calculate the total score for each option (Guo, Zhang, \& Sun, 2008; Deng et al., 2012).

Appropriate technologies are assessed from the four aspects, which are environmental development priorities, economic development priorities, social development priorities and reducing the potential of vulnerability. Stakeholders need to judge based on these indicators to determine the weight distribution. The Delphi method (Zhang, 2010) (expert scoring method) is used to determine the weights. The marking tables collected from 10 experts of relevant city departments were summarized and analyzed. The results are shown in Table 3.

\subsection{Relative Importance of the Options}

There are 16 technologies collected in the field of developing infrastructure, improving monitoring and early warning capabilities and urban development.

1) Sponge City Planning and Operative Technology

2) Urban Water logging Prevention and Control Technology based on the Regulated Drainage System

3) Electricity, Gas and Heat Collaborative Technology of Urban Energy Infrastructure

4) Semi-centralized Quality-divided Water Supply and Drainage System Based on the Separation of Wastewater 
Table 3. The weight of criteria layer.

\begin{tabular}{ccccc}
\hline No. & $\begin{array}{c}\text { Environmental } \\
\text { development } \\
\text { priority }\end{array}$ & $\begin{array}{c}\text { Economic } \\
\text { development } \\
\text { priority }\end{array}$ & $\begin{array}{c}\text { Social } \\
\text { development } \\
\text { priority }\end{array}$ & $\begin{array}{c}\text { Potential of } \\
\text { reducing the } \\
\text { vulnerability }\end{array}$ \\
\hline Average value & 4.3 & 4.4 & 3.6 & 3.4 \\
Normalized value & 0.27 & 0.28 & 0.23 & 0.22 \\
\hline
\end{tabular}

${ }^{*}$ The score range is $0-5$, where 0 indicates no contribution/impact, and 5 points represent the greatest contribution/impact.

5) Key Technology of Long Distance, High Lift and Large Flow in Water Diversion Project

6) Passive Ultra-low Energy Consumption Green Building Construction Technology

7) Roof Greening Technology

8) Permeable Pavement Application Technology

9) Optimization Design Technology of Underground Pipe Network Security and Reliability in Mega City

10) Supporting and Promotion Technology for Urban Infrastructure Design and Construction Standard System Based on Climate Adaption

11) Urban Infrastructure Operational Risk Simulation Warning and Comprehensive Disaster Prevention Technology

12) Transportation Infrastructure Intelligent Monitoring and Maintenance Technology

13) Rapid Detection, Risk Assessment, and Green Reconstruction Technology for Underground Pipeline

14) Systematic Planning Technology for Climate Change Adaptation

15) Urban Green Space Layout Optimization Technology

16) Public Transport Infrastructure Layout Optimization \& Intelligent Operation Technology

As options, the above 16 technologies are assessed from the aspect of environmental development priority, economic development priority, social development priority and reducing the potential of vulnerability The scale of importance judgment is shown in Table 4.

1) The criterion of environmental development priority

With the above scale, the importance judgment matrix of each technology by the criterion of environment development priority is shown in Figure 1.

2) The criterion of economic development priority

The importance judgment matrix of each technology by the criterion of economic development priority is shown in Figure 2.

3) The criterion of social development priority

The importance judgment matrix of each technology by the criterion of social development priority is shown in Figure 3.

4) The criterion of reducing potential of vulnerability

The importance judgment matrix of each technology by the criterion of reducing potential of vulnerability is shown in Figure 4. 
Table 4. Scale of importance judgment.

1 represent that the two elements compared are equally important

3 represent that between the two elements compared, one element is slightly more important

than the other element

5 represent that between the two elements compared, one element is obviously more important than the other element

represent that between the two elements compared, one element is significantly more important than the other element

represent that the two elements compared, one element is extremely more important than the other element

\begin{tabular}{|c|c|c|c|c|c|c|c|c|c|c|c|c|c|c|c|c|}
\hline $\begin{array}{c}\text { Environment } \\
\text { prionity }\end{array}$ & 1 & 2 & 3 & 4 & 5 & 6 & 7 & 8 & 9 & 10 & 11 & 12 & 13 & 14 & 15 & 16 \\
\hline 1 & 1 & 3 & 3 & 1 & 5 & 5 & 1 & 3 & 9 & 9 & 9 & 9 & 9 & 1 & 1 & 9 \\
\hline 2 & $1 / 3$ & 1 & 1 & $1 / 3$ & 3 & 3 & $1 / 3$ & 1 & 7 & 7 & 7 & 7 & 7 & $1 / 3$ & $1 / 3$ & 7 \\
\hline 3 & $1 / 3$ & 1 & 1 & $1 / 3$ & 3 & 3 & $1 / 3$ & 1 & 7 & 7 & 7 & 7 & 7 & $1 / 3$ & $1 / 3$ & 7 \\
\hline 4 & 1 & 3 & 3 & 1 & 5 & 5 & 1 & 3 & 9 & 9 & 9 & 9 & 9 & 1 & 1 & 9 \\
\hline 5 & $1 / 5$ & $1 / 3$ & $1 / 3$ & $1 / 5$ & 1 & 1 & $1 / 5$ & $1 / 3$ & 5 & 5 & 5 & 5 & 5 & $1 / 5$ & $1 / 5$ & 5 \\
\hline 6 & $1 / 5$ & $1 / 3$ & $1 / 3$ & $1 / 5$ & 1 & 1 & $1 / 5$ & $1 / 3$ & 5 & 5 & 5 & 5 & 5 & $1 / 5$ & $1 / 5$ & 5 \\
\hline 7 & 1 & 3 & 3 & 1 & 5 & 5 & 1 & 3 & 9 & 9 & 9 & 9 & 9 & 1 & 1 & 9 \\
\hline 8 & $1 / 3$ & 1 & 1 & $1 / 3$ & 3 & 3 & $1 / 3$ & 1 & 7 & 7 & 7 & 7 & 7 & $1 / 3$ & $1 / 3$ & 7 \\
\hline 9 & $1 / 9$ & $1 / 7$ & $1 / 7$ & $1 / 9$ & $1 / 5$ & $1 / 5$ & $1 / 9$ & $1 / 7$ & 1 & 1 & 1 & 1 & 1 & $1 / 9$ & $1 / 9$ & 1 \\
\hline 10 & $1 / 9$ & $1 / 7$ & $1 / 7$ & $1 / 9$ & $1 / 5$ & $1 / 5$ & $1 / 9$ & $1 / 7$ & 1 & 1 & 1 & 1 & 1 & $1 / 9$ & $1 / 9$ & 1 \\
\hline 11 & $1 / 9$ & $1 / 7$ & $1 / 7$ & $1 / 9$ & $1 / 5$ & $1 / 5$ & $1 / 9$ & $1 / 7$ & 1 & 1 & 1 & 1 & 1 & $1 / 9$ & $1 / 9$ & 1 \\
\hline 12 & $1 / 9$ & 17 & $1 / 7$ & $1 / 9$ & $1 / 5$ & $1 / 5$ & $1 / 9$ & $1 / 7$ & 1 & 1 & 1 & 1 & 1 & 19 & $1 / 9$ & 1 \\
\hline 13 & $1 / 9$ & $1 / 7$ & $1 / 7$ & $1 / 9$ & $1 / 5$ & $1 / 5$ & $1 / 9$ & $1 / 7$ & 1 & 1 & 1 & 1 & 1 & $1 / 9$ & $1 / 9$ & 1 \\
\hline 14 & 1 & 3 & 3 & 1 & 5 & 5 & 1 & 3 & 9 & 9 & 9 & 9 & 9 & 1 & 1 & 9 \\
\hline 15 & 1 & 3 & 3 & 1 & 5 & 5 & 1 & 3 & 9 & 9 & 9 & 9 & 9 & 1 & 1 & 9 \\
\hline 16 & $1 / 9$ & $1 / 7$ & $1 / 7$ & $1 / 9$ & $1 / 5$ & 15 & $1 / 9$ & $1 / 7$ & 1 & 1 & 1 & 1 & 1 & $1 / 9$ & $1 / 9$ & 1 \\
\hline
\end{tabular}

Figure 1. Matrix of environmental development priority.

\begin{tabular}{|c|c|c|c|c|c|c|c|c|c|c|c|c|c|c|c|c|}
\hline $\begin{array}{c}\text { Eavironment } \\
\text { prionity }\end{array}$ & 1 & 2 & 3 & 4 & 5 & 6 & 7 & 8 & 9 & 10 & 11 & 12 & 13 & 14 & 15 & 16 \\
\hline 1 & 1 & 1 & 1 & 5 & $1 / 3$ & 5 & 1 & $1 / 3$ & 5 & 5 & 5 & $1 / 3$ & 5 & 1 & 1 & 3 \\
\hline 2 & 1 & 1 & 1 & 5 & $1 / 3$ & 5 & 1 & $1 / 3$ & 5 & 5 & 5 & $1 / 3$ & 5 & 1 & 1 & 3 \\
\hline 3 & 1 & 1 & 1 & 5 & $1 / 3$ & 5 & 1 & $1 / 3$ & 5 & 5 & 5 & $1 / 3$ & 5 & 1 & 1 & 3 \\
\hline 4 & $1 / 5$ & 15 & $1 / 5$ & 1 & $1 / 7$ & 1 & $1 / 5$ & $1 /$ & 1 & 1 & 1 & $1 /$ & 1 & $1 / 5$ & $1 / 5$ & $1 / 3$ \\
\hline 5 & 3 & 3 & 3 & 7 & 1 & 7 & 3 & 1 & 7 & 7 & 7 & 1 & 7 & 3 & 3 & 5 \\
\hline 6 & $1 / 5$ & 15 & $1 / 5$ & 1 & $1 / 7$ & 1 & $1 / 5$ & $1 /$ & 1 & 1 & 1 & $1 /$ & 1 & $1 / 5$ & $1 / 5$ & $1 / 3$ \\
\hline 7 & 1 & 1 & 1 & 5 & $1 / 3$ & 5 & 1 & $1 / 3$ & 5 & 5 & 5 & $1 / 3$ & 5 & 1 & 1 & 3 \\
\hline 8 & 3 & 3 & 3 & 7 & 1 & 7 & 3 & 1 & 7 & 7 & 7 & 1 & 7 & 3 & 3 & 5 \\
\hline 9 & $1 / 5$ & 15 & 15 & 1 & $1 / 7$ & 1 & $1 / 5$ & $1 /$ & 1 & 1 & 1 & $1 / 7$ & 1 & $1 / 5$ & $1 / 5$ & $1 / 3$ \\
\hline 10 & $1 / 5$ & 15 & $1 / 5$ & 1 & $1 / 7$ & 1 & $1 / 5$ & $1 / 7$ & 1 & 1 & 1 & $1 /$ & 1 & $1 / 5$ & $1 / 5$ & $1 / 3$ \\
\hline 11 & $1 / 5$ & $1 / 5$ & $1 / 5$ & 1 & $1 / 7$ & 1 & $1 / 5$ & $1 / 7$ & 1 & 1 & 1 & $1 / 7$ & 1 & $1 / 5$ & $1 / 5$ & $1 / 3$ \\
\hline 12 & 3 & 3 & 3 & 7 & 1 & 7 & 3 & 1 & 7 & 7 & 7 & 1 & 7 & 3 & 3 & 5 \\
\hline 13 & $1 / 5$ & 15 & $1 / 5$ & 1 & $1 / 7$ & 1 & $1 / 5$ & $1 / 7$ & 1 & 1 & 1 & $1 / 7$ & 1 & $1 / 5$ & $1 / 5$ & $1 / 3$ \\
\hline 14 & 1 & 1 & 1 & 5 & $1 / 3$ & 5 & 1 & $1 / 3$ & 5 & 5 & 5 & $1 / 3$ & 5 & 1 & 1 & 3 \\
\hline 15 & 1 & 1 & 1 & 5 & $1 / 3$ & 5 & 1 & $1 / 3$ & 5 & 5 & 5 & $1 / 3$ & 5 & 1 & 1 & 3 \\
\hline 16 & $1 / 3$ & $1 / 3$ & $1 / 3$ & 3 & $1 / 5$ & 3 & $1 / 3$ & $1 / 5$ & 3 & 3 & 3 & $1 / 5$ & 3 & $1 / 3$ & $1 / 3$ & 1 \\
\hline
\end{tabular}

Figure 2. Matrix of economic development priority. 


\begin{tabular}{|c|c|c|c|c|c|c|c|c|c|c|c|c|c|c|c|c|}
\hline $\begin{array}{c}\text { Social } \\
\text { prionity }\end{array}$ & 1 & 2 & 3 & 4 & 5 & 6 & 7 & 8 & 9 & 10 & 11 & 12 & 13 & 14 & 15 & 16 \\
\hline 1 & 1 & 3 & 1 & 7 & 9 & 5 & 1 & 1 & 5 & 5 & 3 & 7 & 3 & 1 & 3 & 3 \\
\hline 2 & $1 / 3$ & 1 & $1 / 3$ & 5 & 7 & 3 & $1 / 3$ & $1 / 3$ & 3 & 3 & 1 & 5 & 1 & $1 / 3$ & $1 / 3$ & 1 \\
\hline 3 & 1 & 3 & 1 & 7 & 9 & 5 & 1 & 1 & 5 & 5 & 3 & 7 & 3 & 1 & 3 & 3 \\
\hline 4 & $1 / 7$ & $1 / 5$ & $1 /$ & 1 & 3 & $1 / 3$ & $1 /$ & $1 / 7$ & $1 /$ & $1 / 3$ & $1 / 5$ & 1 & $1 / 5$ & $1 /$ & $1 / 7$ & $1 / 5$ \\
\hline 5 & $1 / 9$ & $1 /$ & $1 / 9$ & $1 / 3$ & 1 & $1 / 5$ & $1 / 9$ & $1 / 9$ & $1 / 5$ & $1 / 5$ & $1 /$ & $1 / 3$ & $1 /$ & $1 /$ & $1 / 9$ & $1 /$ \\
\hline 6 & $1 / 5$ & $1 / 3$ & $1 / 5$ & 3 & 5 & 1 & $1 / 5$ & $1 / 5$ & 1 & 1 & $1 / 3$ & 3 & $1 / 3$ & $1 / 5$ & $1 / 5$ & $1 / 3$ \\
\hline 7 & 1 & 3 & 1 & 7 & 9 & 5 & 1 & 1 & 5 & 5 & 3 & 7 & 3 & 1 & 3 & 3 \\
\hline 8 & 1 & 3 & 1 & 7 & 9 & 5 & 1 & 1 & 5 & 5 & 3 & 7 & 3 & 1 & 3 & 3 \\
\hline 9 & $1 / 5$ & $1 / 3$ & $1 / 5$ & 3 & 5 & 1 & $1 / 5$ & $1 / 5$ & 1 & 1 & $1 / 3$ & 3 & $1 / 3$ & 15 & $1 / 5$ & $1 / 3$ \\
\hline 10 & $1 / 5$ & $1 / 3$ & $1 / 5$ & 3 & 5 & 1 & $1 / 5$ & $1 / 5$ & 1 & 1 & $1 / 3$ & 3 & $1 / 3$ & $1 / 5$ & $1 / 5$ & $1 / 3$ \\
\hline 11 & $1 / 3$ & 1 & $1 / 3$ & 5 & 7 & 3 & $1 / 3$ & $1 / 3$ & 3 & 3 & 1 & 5 & 1 & $1 / 3$ & $1 / 3$ & 1 \\
\hline 12 & $1 / 7$ & $1 / 5$ & $1 / 7$ & 1 & 3 & $1 / 3$ & $1 / 7$ & $1 / 7$ & $1 / 3$ & $1 / 3$ & $1 / 5$ & 1 & $1 / 5$ & $1 /$ & $1 / 7$ & $1 / 5$ \\
\hline 13 & $1 / 3$ & 1 & $1 / 3$ & 5 & 7 & 3 & $1 / 3$ & $1 / 3$ & 3 & 3 & 1 & 5 & 1 & $1 / 3$ & $1 / 3$ & 1 \\
\hline 14 & 1 & 3 & 1 & 7 & 9 & 5 & 1 & 1 & 5 & 5 & 3 & 7 & 3 & 1 & 3 & 3 \\
\hline 15 & 1 & 3 & 1 & 7 & 9 & 5 & 1 & 1 & 5 & 5 & 3 & 7 & 3 & 1 & 3 & 3 \\
\hline 16 & $1 / 3$ & 1 & $1 / 3$ & 5 & 7 & 3 & $1 / 3$ & $1 / 3$ & 3 & 3 & 1 & 5 & 1 & $1 / 3$ & $1 / 3$ & 1 \\
\hline
\end{tabular}

Figure 3. Matrix of social development priority.

\begin{tabular}{|c|c|c|c|c|c|c|c|c|c|c|c|c|c|c|c|c|}
\hline Volinerbithy & 1 & 2 & 3 & 4 & 5 & 6 & 7 & 8 & 9 & 10 & 11 & 12 & 13 & 14 & 15 & 16 \\
\hline 1 & 1 & 1 & 1 & 7 & 1 & 3 & 1 & 1 & 1 & 1 & 1 & 1 & 1 & 1 & 1 & 3 \\
\hline 2 & 1 & 1 & 1 & 7 & 1 & 3 & 1 & 1 & 1 & 1 & 1 & 1 & 1 & 1 & 1 & 3 \\
\hline 3 & 1 & 1 & 1 & 7 & 1 & 3 & 1 & 1 & 1 & 1 & 1 & 1 & 1 & 1 & 1 & 3 \\
\hline 4 & 17 & $1 n$ & $1 n$ & 1 & $1 / 7$ & $1 / 5$ & $1 n$ & $1 / n$ & $1 n$ & $1 n$ & $1 n$ & $1 n$ & $1 / n$ & 17 & 17 & $1 / 5$ \\
\hline 5 & 1 & 1 & 1 & 7 & 1 & 3 & 1 & 1 & 1 & 1 & i & 1 & 1 & 1 & 1 & 3 \\
\hline 6 & $1 / 3$ & $1 / 3$ & 13 & 5 & $1 / 3$ & 1 & $1 / 3$ & $1 / 3$ & $1 / 3$ & $1 / 3$ & $1 / 3$ & 13 & $1 / 3$ & $1 / 3$ & $1 / 3$ & 1 \\
\hline 7 & 1 & 1 & 1 & 7 & 1 & 3 & 1 & 1 & 1 & 1 & 1 & 1 & 1 & 1 & 1 & 3 \\
\hline 8 & 1 & 1 & 1 & 7 & 1 & 3 & 1 & 1 & 1 & 1 & 1 & 1 & 1 & 1 & 1 & 3 \\
\hline 9 & 1 & 1 & 1 & 7 & 1 & 3 & 1 & 1 & 1 & 1 & 1 & 1 & 1 & 1 & 1 & 3 \\
\hline 10 & 1 & 1 & 1 & 7 & 1 & 3 & 1 & 1 & 1 & 1 & 1 & 1 & 1 & 1 & 1 & 3 \\
\hline 11 & 1 & 1 & 1 & 7 & 1 & 3 & 1 & 1 & 1 & 1 & 1 & 1 & 1 & 1 & 1 & 3 \\
\hline 12 & 1 & 1 & 1 & 7 & 1 & 3 & 1 & 1 & 1 & 1 & 1 & 1 & 1 & 1 & 1 & 3 \\
\hline 13 & 1 & 1 & 1 & 7 & 1 & 3 & 1 & 1 & 1 & 1 & 1 & 1 & 1 & 1 & 1 & 3 \\
\hline 14 & 1 & 1 & 1 & 7 & 1 & 3 & 1 & 1 & 1 & 1 & 1 & 1 & 1 & 1 & 1 & 3 \\
\hline 15 & 1 & 1 & 1 & 7 & 1 & 3 & 1 & 1 & 1 & 1 & 1 & 1 & 1 & 1 & 1 & 3 \\
\hline 16 & $1 / 3$ & $1 B$ & 13 & 5 & $1 / 3$ & 1 & 13 & 13 & $1 / 3$ & $1 / 3$ & $1 / 3$ & $1 / 3$ & 13 & $1 / 3$ & $1 / 3$ & 1 \\
\hline
\end{tabular}

Figure 4. Matrix of reducing potential of vulnerability.

\subsection{Scoring the Priorities of Options}

The AHP software PriEsT-allinone V2.1 was used to calculate, and the results are shown as Figure 5.

After the evaluation, the options are ranked from high score to low score, the following 6 technologies are selected as the climate change adaption technologies suitable for Chinese cities, and the results are shown as Table 5.

\section{Conclusion}

Through the in-depth analysis of the concept and connotation of climate change, climate disasters and urban adaptation to climate change, we determined the 


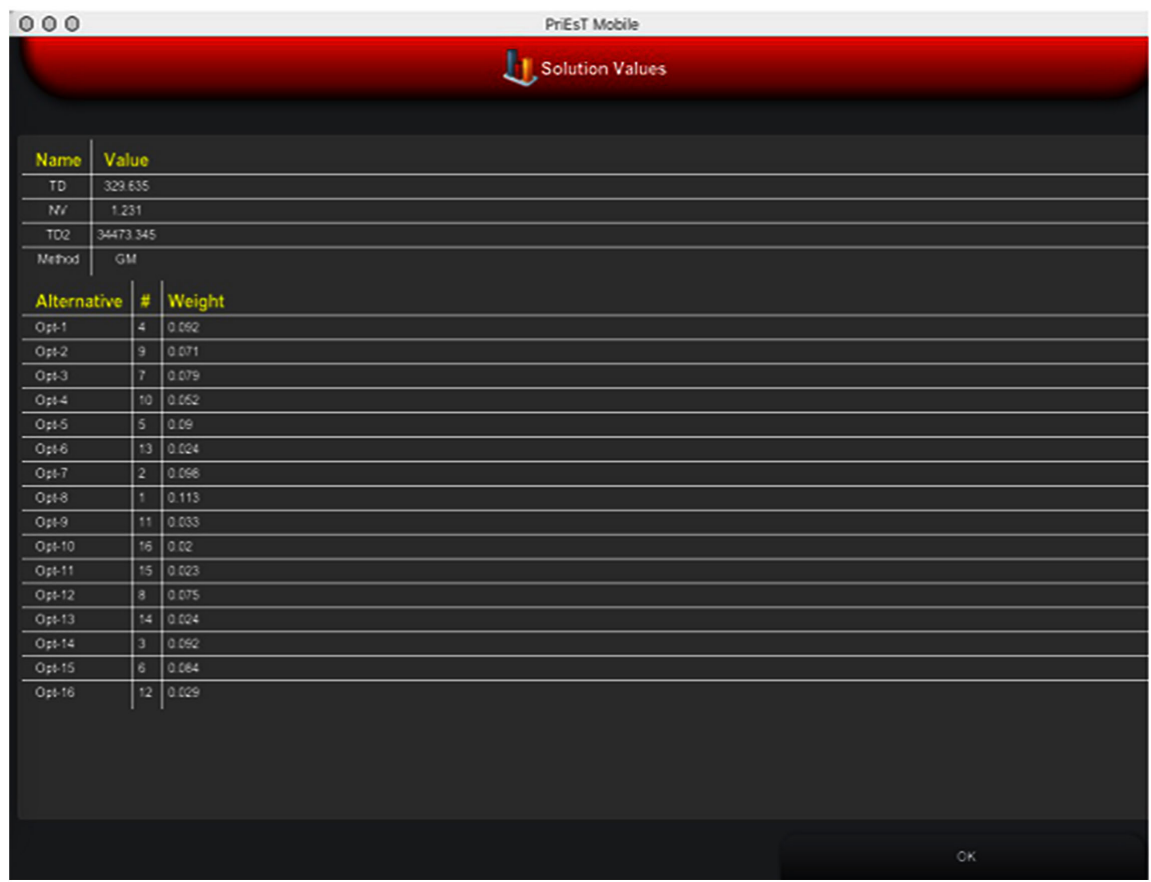

Figure 5. The ranking results of option priorities.

Table 5. List of climate change adaption technologies of Chinese cities.

\begin{tabular}{cc}
\hline No. & Priority Adaption Technology \\
\hline 1 & Sponge City Planning and Operative Technology \\
2 & Systematic Planning Technology for Climate Change Adaptation \\
3 & Urban Green Space Layout Optimization Technology \\
4 & Key Technology of Long Distance, High Lift and Large Flow in Water Diversion Project \\
5 & Roof Greening Technology \\
6 & Permeable Pavement Application Technology \\
\hline
\end{tabular}

framework and steps of urban adaptation to climate change technology. First, we determined the main climate change risks of cities and risk factors such as exposure and vulnerability. Second, for different risks, we identified and determined the priority areas and subsectors of urban adaptation to climate change in China, determined and optimized the climate change adaptation technologies to reduce vulnerability and exposure. Finally, based on the scoring results of experts, we selected the three priority areas for research, and according to the relevant national conditions and principles of climate change mitigation, we identified 6 priority application technologies which could improve the overall efficiency of sustainable development, improve the ability to adapt to climate change and reduce the costs.

According to the evaluation framework and steps of the evaluation, evaluation method and evaluation procedure for each step were given. Finally, through the choice of specific priority subsectors and priority application technologies, we 
laid a solid technical foundation for the country to develop urban planning and provide technical support to pilot work of China's urban adaptation to climate change.

\section{Acknowledgements}

This study was financially supported by the National Natural Science Foundation of China (Grant No. 41505125), China Clean Development Mechanism Fund Grant Project (Grant No. 2014042) and Environmental Defense Fund Project (Grant No. 52062018023).

\section{Conflicts of Interest}

The authors declare no conflicts of interest regarding the publication of this paper.

\section{References}

Deng, X., Li, J. M., Zeng, J. H., Chen, J. Y., \& Zhao, J. F. (2012). Analysis and Application Research on Weight Calculation Method of Analytic Hierarchy Process. Practice and Understanding of Mathematics, 42, 92-100.

$\mathrm{Du}, \mathrm{L}$. (2014). Analysis on the Causes, Impacts and Countermeasures of Climate Change Policy Adjustment in the United States. Chinese Soft Science, 4, 5-13.

Feng, X. Z., \& Zhou, J. B. (2012). A Comparative Study on the Adaptation to Climate Change in China and Australia. Environment and Sustainable Development, 37, 56-60.

Guo, J. Y., Zhang, Z. B., \& Sun, Q. Y. (2008). Study and Applications of Analytic Hierarchy Process. Chinese Safety Science Journal, 18, 148-153.

Han, R. Q., Pan, T., Liu, Y. J., Zhang, J. T., \& Wang, W. T. (2012). The Integrated Innovation System of Agricultural Adaptation to Climate Change in the North China Plain. Progress in Geographical Science, 31, 1537-1545.

IPCC (2007). Climate Change 2007: Impacts, Adaptation and Vulnerability. Contribution of Working Group II to the Fourth Assessment Report of the Intergovernmental Panel on Climate Change (pp. 1-976). Cambridge, UK: Cambridge University Press.

Li, H., Zhang, Y. P., \& Cheng, Y. Q. (2008). The Concept of Vulnerability and Its Evaluation Method. Progress in Geographical Science, 27, 18-25.

Liu, W. D., Ge, Y. H., \& He, Y. (2010) Effects of Climate Change on Occurrence and Development of Rice Diseases and Insect Pests. Chinese Agricultural Science Bulletin, 26, 243-246.

Luo, Y. L. (2012) Changes in Extreme Weather and Climate Events. Advances in Climate Change Research, 8, 90-98.

Ma, T., Mao, L. Q., \& Shen, H. B. (2014). Adaptation Strategies of Climate Change and Its Implications for China. World Environment, 2, 60-63.

Meng, X., \& Li, B. (2013). Multi Objective Decision Analysis Model and Its Application. Modern Management Science, 7, 42-44.

Wang, X. Q. (2005). Decision Economics Research. Beijing: Minzu University of China.

Yin, S., Sun, C., \& Li, J. P. (2012). Decision Factors of Disaster Risk and Its Management. Advances in Climate Change Research, 8, 84-89.

Zeng, J. J., \& Qu, J. S. (2013). EU Climate Change Adaptation Policy Action and Its Im- 
plications. World Geographic Research, 22, 117-126.

Zhang, Y. L. (2010). A Stepwise Assessment Model for Emergency Capability Based on Delphi Method and Minimum Distinction. Chinese Safety Science Journal, 20, 165-170.

Zheng, F., Sun, C., \& Li, J. P. (2012). Understanding Disaster Risk, Exposure, Vulnerability and Resilience from a New Perspective on Climate Change. Advances in Climate Change Research, 8, 79-83.

Zuo, J. (1987). A Method of Sensitivity Analysis in Multi Objective Decision Making. System Engineering Theory and Practice, 7, 1-11. 